\title{
Second Generation TKI before and after Stem Cell Transplant for CML Blast Crisis in the Era of Precision Medicine, Where Do We Go from There?
}

\section{Shatha Farhan*}

Stem Cell Transplant Program, Henry Ford Hospital, USA

Despite the great advances in Tyrosine Kinase Inhibitors (TKI) in treatment of Chronic Myeloid Leukemia (CML) and great improvement in patients quality of life, those who progress to blast crisis still have dismal outcome [1]. The pathogenesis and mechanisms of progression of CML from chronic phase to Advance Phase (AP) or Blast Crisis (BC), including genetic instability and centrosomal aberrations, is complex and still not fully understood [2]. Hence, consensus on an optimal treatment approach has not been achieved.

$\mathrm{Yu}$ and colleagues [3] presented clinical outcome of four young patients (age 28-52) with CML-BC. Three of these patients received imatinib and progressed on it. Two of the 4 patients received second generation TKI to reduce the burden of disease before Stem Cell Transplant (SCT) while the other two patients received second generation TKI to treat relapse of BC after SCT and help revert to complete donor chimerism. After SCT, the first 2 patients were free of progression for almost 2 years (22 and 23 months) and the last 2 patients were also free of progression after second generation TKI for almost 2 years ( 21 and 25 months). It is safe and reasonable approach to use second generation TKI pre SCT without adverse effect on liver or engraftment [4]. SCT with individualized intervention after TKI therapy is superior to TKI alone for CML-BC [5]. Other than being young, these 4 patients did not have any evidence of clonal evolution or other genetic abnormalities and they were able to receive myoablative conditioning regimen before SCT. In a study in which the outcomes of 28 patients receiving reduced intensity conditioning were compared to those of 56 recipients of myeloablative SCT matched for disease severity and stage, reduced intensity recipients had higher rates of relapse [6], In a multivariate analysis done by Jain and colleagues on 477 patients with CML-BC, myeloid immunophenotype, prior TKI, age $>58$ years, lactate dehydrogenase level $>1227$ IU/L, platelet count $<102 \mathrm{~K} / \mathrm{lL}$, no history of stem cell transplantation, transition to $\mathrm{BC}$ from chronic phase/AP, and the presence of chromosome 15 aberrations predicted for a significantly increased risk of death [7]. Interestingly, the first two patients described by Yu et al. had almost 2 years of no progression post SCT without prophylactic or maintenance TKI post SCT. Zhao et al. reported outcome of 12 patients ( $8 \mathrm{BC}$ and $4 \mathrm{AP}$ ) who were treated with second generation TKI, followed by allo-SCT. However, prophylactic dasatinib or nilotinb was administrated after transplantation in 9 patients. After a median follow-up of 28 months after SCT, 8 (66.7\%) were alive [8]. The benefit of prophylactic versus the preemptive use of TKI post SCT is not clear. Nowadays especially that most patients with CML BC referred to SCT are high risk patients and the use of reduced intensity regimens for older patients are on the rise, most centers use the prophylactic approach. However if maintenance is not performed, mandatory close monitoring of the bcr-abl transcript is required although fluctuation of levels is common as late as 10 years post SCT [9]. But there is no prospective data on what is the best approach regarding effect on survival, graft versus host disease (GVHD), quality of life or cost.

$\mathrm{Yu}$ [3] and others [10] demonstrated encouraging responses to TKI therapy in selected patients with AP or BC relapse of CML after SCT. Dasatinib inhibits Src family tyrosine kinases and T cell receptormediated signal transduction and cytokine production [11] and was proposed as a new therapeutic opportunity for GVHD. However, in this report patient number 3 had relapse of GVHD but control of CML after starting dasatinib. In this report patient 4 and others reported durable response using nilotinib for relapse, associated with reconstitution of full-donor chimerism without any signs of GVHD [12].

Further preclinical and clinical studies are needed to assess the pathogenesis of CML BC, high risk features, and individual influence of different TKIs on chimerism, graft versus leukemia, GVHD and other transplant-related toxicity and outcome (Figure 1).

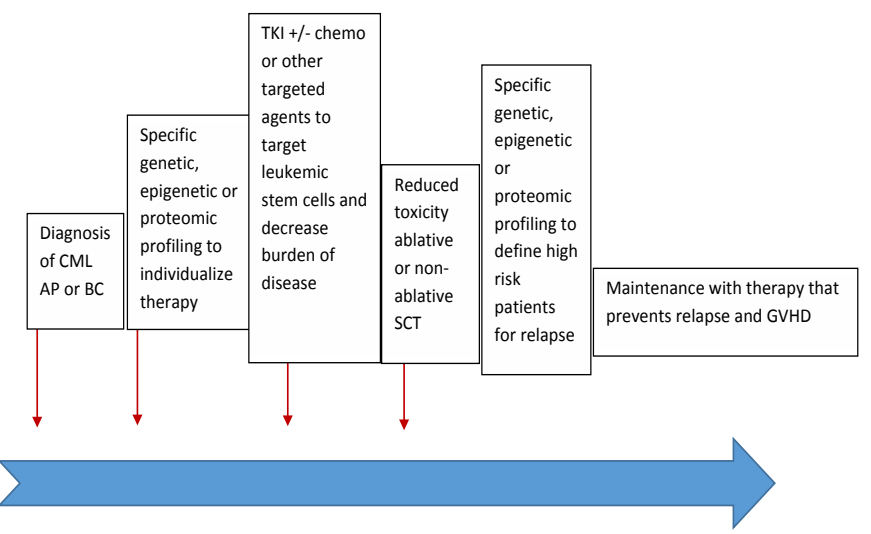

Figure 1: Potential future treatment schema

AP: Accelerated Phase; BC: Blast Crisis; GVHD: Graft Versus Host Disease; SCT: Stem Cell Transplant; TKI: Tyrosine Kinase Inhibitor.

*Corresponding author: Shatha Farhan, MD, Stem Cell Transplant Program, Henry Ford Hospital, CFP5, 2799 W Grand Blvd, Detroit, MI 48202, USA, Tel: 313-713-3910; Fax: 313-916-7911; E-mail: Sfarhan1@hfhs.org

Received August 30, 2017; Accepted September 13, 2017; Published September 25,2017

Citation: Farhan S (2017) Second Generation TKI before and after Stem Cell Transplant for CML Blast Crisis in the Era of Precision Medicine, Where Do We Go from There? J Stem Cell Res Ther 7: 401. doi: 10.4172/2157-7633.1000401

Copyright: (c) 2017 Farhan S. This is an open-access article distributed under the terms of the Creative Commons Attribution License, which permits unrestricted use, distribution, and reproduction in any medium, provided the original author and source are credited. 
Citation: Farhan S (2017) Second Generation TKI before and after Stem Cell Transplant for CML Blast Crisis in the Era of Precision Medicine, Where Do We Go from There? J Stem Cell Res Ther 7: 401. doi: 10.4172/2157-7633.1000401

Page 2 of 2

\section{Conflicts of Interest}

The author declares that there is no conflict of interest regarding the publication of this article.

\section{References}

1. Perez-Jacobo F, Tuna-Aguilar E, Demichelis-Gómez R, Crespo-Solís E Valencia-Rocha U, et al. (2015) Prognostic Factors, Response to Treatment, and Survival in Patients With Chronic Myeloid Leukemia in Blast Phase: A Single-Institution Survey. Clin Lymphoma Myeloma Leuk 15: 778-84. [PubMed]

2. Jabbour EJ, Hughes TP, Cortés JE, Kantarjian HM, Hochhaus A (2014) Potential mechanisms of disease progression and management of advanced-phase chronic myeloid leukemia. Leuk Lymphoma 55: 1451-1462. [PubMed]

3. Yu Z, Ding J, Sun A, Ge Z, Chen B, et al. (2017) Second Generation Tyrosine Kinase Inhibitors Combined With Allogeneic Hematopoietic Stem Cell Transplantation Improve the Prognosis of Patients with Chronic Myelogenous Leukemia in Blast Crisis. J Stem Cell Res Ther.

4. Piekarska A, Gil L, Prejzner W, Wiśniewski P, Leszczyńska A, et al. (2015) Pretransplantation use of the second-generation tyrosine kinase inhibitors has no negative impact on the HCT outcome. Ann Hematol 94: 1891-1897. [PubMed]

5. Jiang H, Xu LP, Liu DH, Liu KY, Chen SS, et al. (2014) Allogeneic hematopoietic SCT in combination with tyrosine kinase inhibitor treatment compared with TKI treatment alone in CML blast crisis. Bone Marrow Transplant 49: 1146-1154. [PubMed]

6. Topcuoglu P, Arat M, Ozcan M, Arslan O, Ihan O, et al. (2012) Case-matched comparison with standard versus reduced intensity conditioning regimen in chronic myeloid leukemia patients. Ann Hematol 91: 577-586. [PubMed]

7. Jain P, Kantarjian HM, Ghorab A, Sasaki K, Jabbour EJ, Nogueras Gonzalez G et al. (2017) Prognostic factors and survival outcomes in patients with chronic myeloid leukemia in blast phase in the tyrosine kinase inhibitor era: Cohort study of 477 patients. Cancer. [PubMed]

8. Zhao Y, Luo Y, Shi J, Cai Z, Huang H, et al. (2014) Second-generation tyrosine kinase inhibitors combined with stem cell transplantation in patients with imatinibrefractory chronic myeloid leukemia. Am J Med Sci 347: 439-445. [PubMed]

9. Arpinati M, Tolomelli G, Bochicchio MT, Castagnetti F, Amabile M, et al (2010) Molecular monitoring of BCR-ABL transcripts after allogeneic stem cell transplantation for chronic myeloid leukemia. Biol Blood Marrow Transplant 19: 735-740. [PubMed]

10. Wright M.P, Shepherd JD, Barnett MJ, Nantel SH, Sutherland HJ, et al. (2010) Response to tyrosine kinase inhibitor therapy in patients with chronic myelogenous leukemia relapsing in chronic and advanced phase following allogeneic hematopoietic stem cell transplantation. Biol Blood Marrow Transplant 16: 639-46. [PubMed]

11. Schade AE, Schieven GL, Townsend R, Jankowska AM, Susulic V, et al. (2008) Dasatinib, a small-molecule protein tyrosine kinase inhibitor, inhibits T-cell activation and proliferation. Blood 111: 1366-1377. [PubMed]

12. Merante S, Colombo AA, Calatroni S, Rocca B, Boni M, Bernasconi $P$, et al. (2009) Nilotinib restores long-term full-donor chimerism in Ph-positive acute lymphoblastic leukemia relapsed after allogeneic transplantation. Bone Marrow Transplant 44: 263-264. [PubMed] 